\title{
Potential probiotics from faecal specimens of breastfed Nigerian infants as a therapy for bacterial gastroenteritis
}

\author{
Adenike A O Ogunshe ${ }^{1}$, Abiodun I Sanni ${ }^{2}$, Daniel K Olukoya ${ }^{3}$
}

Sri Lanka Journal of Child Health, 2011; 40(3): 116-124

DOI: http://dx.doi.org/10.4038/sljch.v40i3. 3509

\begin{abstract}
Objective: To investigate the possibility of isolating indigenous probiotic strains from faecal specimens of breastfed infants.

Method: One hundred and sixty four Lactobacillus strains [Lb. reuteri 72 (43.9\%), Lb. casei $40(24.4 \%)$, Lb. acidophilus 35 (21.3\%), Lb. bifidus 11 (6.71\%), Lb. brevis $3(1.83 \%)$ and Lb. plantarum $3(1.83 \%]$ isolated from fresh, faecal specimens of 57 healthy, breastfed Nigerian infants and children $<12$ months old were assayed for in vitro inhibitory potentials against reference and gastroenteritic bacterial strains, using the modified agar spot and agar well-diffusion methods.
\end{abstract}

Results: Twenty six (15.9\%) of the Lactobacillus strains at 24 hours and 36 months of storage were inhibitory in vitro towards all the gastroenteritic and reference bacteria (Bacillus cereus, Bacillus licheniformis, Citrobacter species, Enterobacter aerogenes, Escherichia coli, Klebsiella aerogenes, Klebsiella pneumoniae, Morganella morganii, Proteus mirabilis, Proteus vulgaris, Pseudomonas aeruginosa. Salmonella enterica var. typhi, Salmonella enterica var. paratyphi, Salmonella enterica var. typhimurium, Salmonella sp., Shigella dysenteriae, Shigella flexneri, Staphylococcus aureus and Yersinia enterocolitica); while only 7 (4.3\%) strains were inhibitory at 60 months of storage. The finally selected $L b$. reuteri $\mathrm{CH} 1$ strain, which was inhibitory against all the indicator and reference bacteria, even at 60 months of storage, also had the lowest antibiotic resistance $(23.3 \%)$, survived 3\% bile and simulated $\mathrm{pH}$ conditions of 3.0-9.5.

${ }^{1}$ Lecturer, Applied Microbiology and Infectious Diseases Unit, ${ }^{2}$ Professor, Food Microbiology Unit, Department of Botany \& Microbiology, University of Ibadan, Ibadan, Nigeria, ${ }^{3}$ Research Scientist, Genetics Unit, Nigeria Institute for Medical Research, P.M.B. 2013, Yaba, Lagos, Nigeria

(Received on 27 June 2010: Accepted after revision on 18 October 2010)
Conclusions: Potential gastroenteriticidal Lactobacillus probiotic strains with longer shelf-life can be obtained from breastfed faecal specimens of Nigerian infants, more especially children above 5 months old.

(Keywords: Breastfeeding; child health; gastroenteritis; infant mortality; Lactobacillus; probiotics)

\section{Background}

Gastroenteritis is still a major worldwide problem among infants and children, and one of the principal causes of infantile sickness and death in more than $85 \%$ of the world population ${ }^{1}$ Although antibiotic therapy has been the mainstay in the treatment of diarrhoeal cases, the onset of drug resistance threatens virtually all classes of antibacterial agents ${ }^{2}$ and though the magnitude of the problem may vary from place to place, the problem of antibiotic resistance is quite alarming in tropical developing countries. Several workers in this country and elsewhere have also highlighted the problems of antibiotic resistance ${ }^{3,4}$ An alternative therapeutic approach, based on oral administration of live bacteria has therefore been under active consideration $5,6,7,8$.

More than $95 \%$ of infants in Africa are currently breastfed but feeding practices are often inadequate and the importance of breast milk as a food resource in African countries is also not generally recognised ${ }^{9}$. Although it is important that babies are given extra food, as well as breast milk, at the right age and in sufficient amounts, to enable them grow and stay healthy, new studies on breastfeeding have also discovered or confirmed the benefits of breastfeeding to mother and child ${ }^{10}$, while human milk has also been found to contain several antiviral and antibacterial factors ${ }^{11}$

In a study with data from India, Peru and Ghana on hospitalisation for diarrhoeal and respiratory illness ${ }^{12}$, non-breastfed infants had a higher risk of all causes of hospitalisation when compared to infants who had 
been predominantly breastfed and also had a higher diarrhoea-specific hospitalisation. Similarly, nonbreastfed infants had higher risk of dying when compared to infants who had been predominantly breastfed. There have been many current attempts to prove the protective factors demonstrated in human milk, and that breastfeeding has a defensive role against various infections in infants. As earlier reported, information about the human flora has mostly been gathered from faeces, and many of the validly described gut Lactobacillus species have been isolated from human faeces ${ }^{13}$. The aim of this study is therefore to determine the possibility of isolating Lactobacillus species from infantile faecal flora of breastfed infants that can serve as probiotics of clinical importance, especially in infantile gastroenteritic therapy.

\section{Methods}

\section{Collection of specimens and isolation of} gastroenteritic isolates

Stool and vomitus specimens were obtained from gastroenteritic epidemic victims in three eastern states of Nigeria and from gastroenteritic patients at Oni Memorial Children Hospital, Ibadan, Nigeria. The stool and vomitus specimens were collected in alkaline peptone water at $\mathrm{pH} 8.6$, and immediately transported to the laboratory for the preliminary microbiological analysis on molten $\left(45^{\circ} \mathrm{C}\right)$ nutrient agar (NA) (Oxoid, Basingstoke, England), thiosulphate citrate bile sucrose agar (TCBS) (Oxoid) agar, pH 8.2; deoxycholate citrate agar (DCA) (Oxoid), pH 7.2; MacConkey agar (Oxoid), cystein lactose electrolyte deficient agar (CLED) (LAB M, Topley House, Lancashire, England) and SalmonellaShigella agar (LAB M) at pH 7.4. Representatives of each different bacterial colony types were randomly picked from the primary culture plates of each specimen and sub-cultured on sterile NA and CLED plates by the streaking method. All the pure bacterial isolates from the gastroenteritic specimens were kept in triplicates on Brain Heart Infusion (BHI) (Oxoid) agar slants as working and stock cultures. Final identification analysis was carried out at the Nigeria Institute of Medical Research (NIMR) laboratories according to standard taxonomic tools ${ }^{14}$.

\section{Isolation and characterisation of Lactobacillus strains}

Ethical approval was granted by the Institute of Child Health and Department of Paediatrics, University College Hospital ( $\mathrm{UCH})$, Ibadan, Nigeria for the collection of faecal specimens from subjects at the
Institute of Child Health, UCH, Ibadan, Nigeria. Subjects were also solicited by providing questionnaires to parents during their visits to postnatal clinics and at family homes. Questionnaires were completed by providing demographic information and details of feeding patterns of the child prior to collection of the stool specimen. Information sought through the questionnaires included age, sex, term of child at birth (full term, premature or post-mature), feeding patterns of the children and antibiotic therapy within 5 weeks prior to collection of fresh faecal specimens. Faecal specimens of three children who were on antibiotic therapy within the stipulated time period were excluded from analysis.

One ml volumes of overnight MRS broth cultures (de Man, Rogosa and Sharpe, Oxoid, Basingstoke, England) of the infantile faecal specimens from healthy children at $\mathrm{pH}$ 5.5-5.7 were separately transferred to sterile Petri dishes by the pour-plate method before incubation anaerobically in $5 \% \mathrm{CO}_{2}$ (Gas Pak Anaerobic System, Oxoid, Basingstoke, England) at $32-35^{\circ} \mathrm{C}$ for $24-48$ hours. Representatives of each different bacterial colony type were randomly picked from the primary plates of each specimen and repeatedly sub-cultured on to sterile MRS agar plates to obtain pure cultures.

Different randomly isolated Lactobacillus strains were phenotypically identified at genus and species level by classical tests including the analysis of cell morphology, homo/heterofermentative and biochemical characters, sugar fermentation patterns and growth at different temperatures. The Lactobacillus strains were examined microscopically, and initial confirmation and grouping of the lactobacilli was based on Gram's reaction, catalase reaction with hydrogen peroxide, growth at $15^{\circ} \mathrm{C}$ and $45^{\circ} \mathrm{C}$ in MRS and medium, gas and acid production from glucose and fermentation of lactose, sucrose, arabinose, fructose and mannitol ${ }^{15}$.

The isolates that met the preliminary identification criteria were separately grown in replicates overnight (18-24 hours) in $10 \mathrm{ml}$ Rogosa broth at $35^{\circ} \mathrm{C}$ until the weight of the cell mass obtained was $0.05-0.1 \mathrm{~g}$. The purity of the strains was checked, and the cells were washed twice in $0.9 \%$ sterile $\mathrm{NaCl}$ solution after centrifuging. The isolates were then stored at $4^{0} \mathrm{C}$ in Hogness freezing buffer $\left(3.6 \mathrm{mM} \mathrm{K}_{2} \mathrm{HPO}_{4} ; 1.3 \mathrm{mM}\right.$ $\mathrm{KH}_{2} \mathrm{PO}_{4} ; 2.0 \mathrm{mM}$ Na-citrate; $1.0 \mathrm{mM} \mathrm{MgSO}_{4} ; 12 \%$ glycerol) and kept frozen. Additional taxonomic studies were carried out on the purified isolates on the basis of their cultural, morphological, biochemical and physiological characteristics and 
sugar fermentation patterns. Final identification analysis was carried out at the laboratories of Nigeria Institute of Medical Research (NIMR), Department of Medical Microbiology \& Parasitology, University College Hospital, Ibadan and Department of Botany \& Microbiology, University of Ibadan according to standard taxonomic tools ${ }^{16,17}$.

\section{Antibiotic susceptibility testing}

Agar disc-diffusion method: The gastroenteritic bacterial pathogens were assayed for their susceptibility / resistance patterns using the agar discdiffusion method. Sterile Mueller-Hinton agar, nutrient agar, brain heart infusion agar, tryptone soy agar and MacConkey agar plates were seeded with each of the indicator (gastroenteritic) isolates, after which antibiotic discs commonly used for routine studies in the country, were aseptically placed on the seeded agar surfaces. After overnight incubation at $35^{\circ} \mathrm{C}$, zones of inhibition were recorded in $\mathrm{mm}$ diameter $^{18}$ Zones less than $10 \mathrm{~mm}$ in diameter or absence of zones of inhibition were recorded as negative / no inhibition.

Modified agar spot-diffusion method: The antibiotic susceptibility test for the gastroenteritic bacterial species using paediatric antibiotic suspensions was determined according to the modified ${ }^{19}$ agar spotdiffusion method of Tagg and Dajani ${ }^{20}$. Sterile agar plates were seeded with the indicator organisms by streaking the entire surface of the culture plates (as indicated above), followed by separately dispensing the modified broth cultures $(250 \mu \mathrm{l}, 500 \mu \mathrm{l}, 750 \mu \mathrm{l}$, $1000 \mu \mathrm{l}$ ) (soft agar) of the putative organisms (Lactobacillus strains) on the agar surface and incubated at $35^{\circ} \mathrm{C}$ for $24-48$ hours. The demonstration of antagonism depends on the release of a diffusible inhibitor early in the growth phase of the putative organisms into the assay media. Inhibitory zones surrounding the putative organisms were noted and recorded in $\mathrm{mm}$ diameter. Zones less than $10 \mathrm{~mm}$ in diameter or absence of zones of inhibition were recorded as negative / no inhibition.

Modified agar well-diffusion method: The antibiotic susceptibility test for the gastroenteritic bacterial species using paediatric antibiotic suspensions was also determined according to the modified ${ }^{19}$ agar well-diffusion method of Tagg and Dajani ${ }^{20}$. Holes, 6 $\mathrm{mm}$ in diameter were aseptically bored out of sterile agar plates (as indicated above), which were then seeded with the indicator organisms by streaking the entire surface of the agar plates. Modified broth cultures (soft agar) of the putative organisms $(250 \mu \mathrm{l}$, $500 \mu \mathrm{l}, 750 \mu \mathrm{l}, 1000 \mu \mathrm{l})$ were separately dispensed into the holes and incubated at $35^{\circ} \mathrm{C}$ for $24-48$ hours. The demonstration of antagonism depends on the release into the assay media of a diffusible inhibitor early in the growth phase of the putative microorganisms. Inhibitory zones surrounding the putative bacteria were noted and recorded in $\mathrm{mm}$ diameter. Zones less than $10 \mathrm{~mm}$ in diameter or absence of zones of inhibition were recorded as negative / no inhibition.

The oral paediatric antibiotics used with their generics and batch numbers were: Emgyl [metronidazole] (5558fF, 6178F), Jawaclox [cloxacillin] (D4078, L4040), Evans metronidazole (3C950007, 3H950006), Barbicillin [ampicillin] (0683, 0800). Suphtim [sulfamethoxazole /trimethoprim] (SS05908, SS04805), Faplox [cloxacillin] (AC065, FG049), Barbimycin [erythromycin] (0080, 0977), Throtal [erythromycin] (TD-017, TD-12), Emtrim [septrin] (3173F, 3051H), Evans cotrimoxazole (5H802013, 4H802012), Bactrim [septrin] (LS24196, Ls24109), Primpex [cloxacillin] (03010, 05010), Mopson metronidazole (04-2234, 04-2235), Elgyl [metronidazole] (IU510, IV464) and Nichem ampicillin (A20S, A07S). The antibiotics were all manufactured in Nigeria, as indicated on their packages.

Determination of antibiotic susceptibility of the Lactobacillus strains: The most-inhibitory Lactobacillus strains from infantile faecal samples were screened for their susceptibility to 17 antibiotics used in clinical practice by the agar disc diffusion method on MRS agar. MRS agar plates seeded with each Lactobacillus culture broth were left for about 15 minutes before aseptically placing antibiotic discs on the agar surfaces and incubating the plates anaerobically at $37^{\circ} \mathrm{C}$ for $18-24$ hours. Zones of inhibition and the diameter of the zones were measured and recorded in millimeter diameter ${ }^{21}$. Zones less than $10 \mathrm{~mm}$ in diameter or absence of zones of inhibition were recorded as negative / no inhibition.

Bioassay to determine in vitro inhibitory activities of Lactobacillus species from breast-fed infantile faecal specimens against gastroenteritic bacterial species: Twenty six Lactobacillus strains that exhibited the highest rates of antimicrobial activities against the gastroenteritic indicator (gastroenteritic) organisms within 24 hours and 36 months of storage were further screened for their antimicrobial activities against selected gastroenteritic and reference strains, using the modified agar spot and agar well-diffusion methods. Broth cultures $(250,500750$ and $1000 \mu 1)$ of each of the Lactobacillus strain were separately dispensed into the agar wells in Mueller-Hinton and 
brain-heart infusion agar plates already seeded with the gastroenteritic indicator bacterial species. After overnight incubation at $35^{\circ} \mathrm{C}$, inhibition observed by a clear zones extending laterally from the border of the producer isolates were noted and recorded in $\mathrm{mm}$ diameter $^{22}$ Zones less than $10 \mathrm{~mm}$ in diameter or absence of zones of inhibition were recorded as negative / no inhibition.

\section{Results}

Gastroenteritic bacterial species isolated from epidemic patients ( 7 months - 7 years), hospital inpatients (5 months - 51/2 years) and hospital outpatients ( 9 months $-4 \frac{1}{2}$ years) assayed for in this study were Bacillus cereus (4), Bacillus licheniformis (5), Citrobacter sp. (1), Enterobacter aerogenes (2), Escherichia coli (5), Klebsiella aerogenes (3), Klebsiella pneumoniae (5), Morganella morganii (1), Proteus mirabilis (3), Proteus vulgaris (1), Pseudomonas aeruginosa (1), Salmonella enterica var. Typhi (1), Salmonella enterica var. Paratyphi (1), Salmonella enterica var. Typhimurium (1), Salmonella sp. (1), Shigella dysentariae (1), Shigella flexneri (1), Staphylococcus aureus (2) and Yersinia enterocolitica (1).

The viable counts of the infantile faecal specimens were between $1.1 \times 10^{3}$ and $7.2 \times 10^{3} \mathrm{cfu} \mathrm{ml}^{-1}$. No microbial growth was recorded for faecal specimen $\mathrm{CH} 001$, while no lactobacilli was observed in 16 infantile faecal specimens of subjects 4-16 days old. The 164 Lactobacillus strains randomly isolated from faecal specimens of healthy and well-nourished neonates and infants were characterised in this study. Lactobacillus reuteri (43.9\%), Lactobacillus casei (24.4\%) and Lactobacillus acidophilus (21.3\%) were the most prevalent strains, while Lactobacillus bifidus (6.71\%), Lactobacillus brevis (1.83\%) and Lactobacillus plantarum (1.83\%) were also obtained. There was however, a higher recovery rate of Lactobacillus strains from faecal samples of older healthy infants and children (5-11 months).

The Gram-negative bacterial species from epidemic sources $(n=10)$ exhibited very high $(70-90 \%)$ to total $(100 \%)$ phenotypic resistance towards amoxicillin, ampicillin, augmentin, ceftazone, ceftriazone, chloramphenicol, ciprofloxacin, cotrimoxazole, fortum, gentamicin, nalidixic acid, nitrofurantoin, norfloxacin, ofloxacin, perfloxacin and tetracycline but lowest resistance $(20.0 \%)$ were displayed towards claforan, while the resistance rates among the Gramnegative hospital isolates was between $17.6 \%$ (tarivid) and 88.2\% (amoxicillin, augmentin and ceftriazone). Antibiotic resistance rates were relatively lower among the Gram-negative gastroenteritic bacterial species of hospital sources. Total resistance $(100 \%)$ rates were also recorded among the Gram-positive bacterial strains (epidemic sources) towards more of the antibiotics amoxicillin, augmentin, azithromycin, cefuroxime, cephalexin, ciprofloxacin, clindamycin, cloxacillin, colistin, cotrimoxazole, erythromycin, gentamicin, norfloxacin, ofloxacin, penicillin, rocephine, septrin, streptomycin and tetracycline; while similarly higher resistance rates $(75.0 \%)$ were also exhibited towards claforan and tarivid but lower resistance rates were recorded among the Gram-positive bacteria (Table 1).

The phenotypic antibiotic resistance profiles of the gastroenteritic bacterial isolates from epidemic and hospital specimens showed relatively lower resistance rates towards 30 oral paediatric antibiotic suspensions (when compared to the rates recorded for the antibiotic discs), except towards chloramphenicol, erythromycin, metronidazole and the non-antibiotic anti-gastroenteritic medications (Table 2). However, there were no differences in the antibiotic susceptibility / resistance values on the different culture media.

Twenty six Lactobacillus strains from infantile faecal specimens $L b$. reuteri $11(42.3 \%)$ Lb. casei 7 (26.9\%), Lb. acidophilus 3 (11.5\%), Lb. plantarum 2 (7.7\%), Lb. bifidus 1 (3.8\%), Lb. brevis 1 (3.8\%) exhibited total $(100 \%)$ in vitro inhibition of the gastroenteritic indicator organisms between 24 hours and 36 months of storage but only $4(15.3 \%) \mathrm{Lb}$. reuteri, $2(7.7 \%)$ Lb. acidophilus and 1 (3.8\%) Lb. casei strains were inhibitory towards all the target organisms at 60 months of storage. The finally selected potential probiotic candidate, $L b$. reuteri $\mathrm{CH} 1$ had the lowest resistance $(23.3 \%)$ towards the test antibiotics, survived $3 \%$ physiological bile, simulated $\mathrm{pH}$ (3.0-9.5), and exhibited significant spectrum of inhibitory activities against 7 reference strains and 12 selected gastroenteritic strains from children (Table 3 ). 
Table 1

Phenotypic antibiotic resistance profiles of epidemic and hospital Gram-positive and Gram-negative gastroenteritic bacterial isolates

\begin{tabular}{|c|c|c|c|c|c|c|c|}
\hline \multicolumn{4}{|c|}{ Gram-positive (\% R) } & \multicolumn{4}{|c|}{ Gram-negative (\% R) } \\
\hline $\begin{array}{c}\text { Antibiotics } \\
{[24]}\end{array}$ & $\begin{array}{c}\text { Conc. } \\
(\mu \mathrm{g})\end{array}$ & $\begin{array}{l}\text { Epid. } \\
(n=4)\end{array}$ & $\begin{array}{c}\text { Hospt. } \\
(n=7)\end{array}$ & $\begin{array}{c}\text { Antibiotics } \\
{[21]}\end{array}$ & $\begin{array}{c}\text { Conc. } \\
(\mu \mathrm{g})\end{array}$ & $\begin{array}{c}\text { Epid. } \\
(n=10)\end{array}$ & $\begin{array}{l}\text { Hospt. } \\
(n=17)\end{array}$ \\
\hline Amoxicillin & $25 \mu \mathrm{g}$ & 100.0 & 100.0 & Amoxicillin & $25 \mu \mathrm{g}$ & 100.0 & 88.2 \\
\hline Ampicillin & $10 \mu \mathrm{g}$ & 50.0 & 85.7 & Ampicillin & $25 \mu \mathrm{g}$ & 100.0 & 52.9 \\
\hline Augmentin & $30 \mu \mathrm{g}$ & 100.0 & 100.0 & Augmentin & $30 \mu \mathrm{g}$ & 100.0 & 88.2 \\
\hline \multirow[t]{3}{*}{ Azithromycin } & $10 \mu \mathrm{g}$ & 100.0 & 57.1 & & & & \\
\hline & & & & Ceftazone & $20 \mu \mathrm{g}$ & 100.0 & 52.9 \\
\hline & & & & Ceftriazone & $30 \mu \mathrm{g}$ & 100.0 & 82.4 \\
\hline Cefuroxime & $20 \mu \mathrm{g}$ & 100.0 & 57.1 & & & & \\
\hline Cephalexin & $10 \mu \mathrm{g}$ & 100.0 & 71.4 & & & & \\
\hline Chloramphenicol & $30 \mu \mathrm{g}$ & 50.0 & 42.9 & Chloramphenicol & $25 \mu \mathrm{g}$ & 70.0 & 23.5 \\
\hline Ciprofloxacin & $5 \mu \mathrm{g}$ & 100.0 & 54.5 & Ciprofloxacin & $10 \mu \mathrm{g}$ & 90.0 & 29.4 \\
\hline Ciproxin & $10 \mu \mathrm{g}$ & 50.0 & 71.4 & & & & \\
\hline Claforan & $30 \mu \mathrm{g}$ & 75.0 & 59.5 & Claforan & $30 \mu \mathrm{g}$ & 20.0 & 70.6 \\
\hline Clindamycin & $10 \mu \mathrm{g}$ & 100.0 & 81.8 & & & & \\
\hline Cloxacillin & $5 \mu \mathrm{g}$ & 100.0 & 90.9 & & & & \\
\hline Colistin & $10 \mu \mathrm{g}$ & 100.0 & 100.0 & & & & \\
\hline Cotrimoxazole & $25 \mu \mathrm{g}$ & 100.0 & 100.0 & Cotrimoxazole & $25 \mu \mathrm{g}$ & 100.0 & 58.8 \\
\hline \multirow[t]{2}{*}{ Erythromycin } & $5 \mu \mathrm{g}$ & 100.0 & 85.8 & & & & \\
\hline & & & & Fortum & $30 \mu \mathrm{g}$ & 70.0 & 64.7 \\
\hline \multirow[t]{3}{*}{ Gentamicin } & $10 \mu \mathrm{g}$ & 100.0 & 42.9 & Gentamicin & $10 \mu \mathrm{g}$ & 90.0 & 29.4 \\
\hline & & & & Nalidixic acid & $30 \mu \mathrm{g}$ & 100.0 & 70.6 \\
\hline & & & & Nitrofurantoin & $300 \mu \mathrm{g}$ & 100.0 & 47.1 \\
\hline Norfloxacin & $10 \mu \mathrm{g}$ & 100.0 & 71.4 & Norfloxacin & $10 \mu \mathrm{g}$ & 100.0 & 41.2 \\
\hline Ofloxacin & $30 \mu \mathrm{g}$ & 100.0 & 42.9 & Ofloxacin & $30 \mu \mathrm{g}$ & 70.0 & 41.7 \\
\hline \multirow[t]{2}{*}{ Penicillin } & $15 \mu \mathrm{g}$ & 100.0 & 85.8 & & & & \\
\hline & & & & Perfloxacin & $5 \mu \mathrm{g}$ & 100.0 & 23.5 \\
\hline Rocephine & $30 \mu \mathrm{g}$ & 100.0 & 42.9 & Rocephine & $30 \mu \mathrm{g}$ & 40.0 & 58.8 \\
\hline Septrin & $25 \mu \mathrm{g}$ & 100.0 & 71.4 & Septrin & $25 \mu \mathrm{g}$ & 40.0 & 23.5 \\
\hline Streptomycin & $10 \mu \mathrm{g}$ & 100.0 & 71.4 & & & & \\
\hline Tarivid & $5 \mu \mathrm{g}$ & 75.0 & 57.1 & Tarivid & $5 \mu \mathrm{g}$ & 50.0 & 17.6 \\
\hline \multirow[t]{2}{*}{ Tetracycline } & $10 \mu \mathrm{g}$ & 100.0 & 100.0 & Tetracycline & $30 \mu \mathrm{g}$ & 100.0 & 47.1 \\
\hline & & & & Zinnat & $30 \mu \mathrm{g}$ & 50.0 & 58.8 \\
\hline
\end{tabular}

Table 2

Phenotypic antibiotic resistance profiles of gastroenteritic bacterial isolates from epidemic and hospital specimens using oral paediatric antibiotic suspensions

Antibiotics [30]

Ampicillin-cloxacillin [8]

Cephalexin [6]

Chloramphenicol [2]

Cotrimoxazole [4]

Erythromycin [2]

Metronidazole [8]

NANT [5]
\% Phenotypic antibiotic resistance

Epidemic bacterial isolates

46.2
27.2
100.0
30.6
81.8
77.1
100.0

46.2

27.2

00.0

81.8

77.1

100.0
Hospital bacterial isolates

$\begin{array}{cc}\text { (Vomitus) } & \text { (Faecal) } \\ 43.8 & 52.5 \\ 27.2 & 25.0 \\ 100.0 & 100.0 \\ 43.8 & 70.0 \\ 100.0 & 100.0 \\ 84.4 & 86.1 \\ 100.0 & 100.0\end{array}$

$N A N T=$ non antibiotic anti-gastroenteritic medications 
Table 3

Phenotypic inhibition of indicator bacterial species by the antimicrobial-producing Lb. reuteri CH1 at 24,48 hours incubation at 60 months of storage using modified agar spot and agar well-diffusion methods

$\quad$ Indicator organisms
B. cereus $25 \mathrm{~S}$
B. licheniformis $26 \mathrm{~S}$
Bacillus sp.39S
B. subtilis $\mathrm{NCTC} 8236$
Citrobacter sp.55S
E. coli $\mathrm{K} 12$
E. coli $\mathrm{V} 157$
E. coli $\mathrm{NCTC} 10418$
E. coli $\mathrm{NTCC} 11560$
Kleb. aerogenes $24 \mathrm{~S}$
Kleb. aerogenes $412 \mathrm{~S}$
Kleb. pneumoniae $29 \mathrm{~V}$
Kleb. pneumoniae $32 \mathrm{~S}$
Kleb. pneumoniae $57 \mathrm{~S}$
Pr. mirabilis $22 \mathrm{aS}$
Pr. mirabilis $22 \mathrm{bS}$
Ps. aeruginosa $23 \mathrm{~S}$
V. cholerae $\mathrm{MA}$ Vibrio
V. cholerae $\mathrm{INABA}$

\begin{tabular}{|c|c|}
\hline Source & \\
\hline & $24 h$ \\
\hline stool & $+(18.0)$ \\
\hline stool & $+(14.0)$ \\
\hline stool & $+(12.0)$ \\
\hline Ref. strain & $+(18.0)$ \\
\hline stool & $+(16.0)$ \\
\hline Ref. strain & $+(18.0)$ \\
\hline Ref. strain & $+(16.0)$ \\
\hline Ref. strain & $+(18.0)$ \\
\hline Ref. strain & $+(18.0)$ \\
\hline stool & $+(14.0)$ \\
\hline stool & $+(16.0)$ \\
\hline vomitus & $+(18.0)$ \\
\hline stool & $+(16.0)$ \\
\hline stool & $+(14.0)$ \\
\hline stool & $+(16.0)$ \\
\hline stool & $+(14.0)$ \\
\hline stool & $+(22.0)$ \\
\hline stool & $+(16.0)$ \\
\hline Ref. strain & $+(18.0)$ \\
\hline
\end{tabular}

Zones of inhibition ( $\mathrm{mm}$ diameter)

$\begin{array}{cc}\mathbf{4 8 h} & \mathbf{6 0 m} \\ +(18.0) & +(16.0) \\ +(14.0) & +(14.0) \\ +(12.0) & +(12.0) \\ +(18.0) & +(12.0) \\ +(16.0) & +(12.0) \\ +(18.0) & +(14.0) \\ +(16.0) & +(13.0) \\ +(18.0) & +(16.0) \\ +(18.0) & +(14.0) \\ +(14.0) & +(12.0) \\ +(16.0) & +(15.0) \\ +(18.0) & +(13.0) \\ +(16.0) & +(10.0) \\ +(14.0) & +(12.0) \\ +(16.0) & +(12.0) \\ +(14.0) & +(10.0) \\ +(22.0) & +(20.0) \\ +(20.0) & +(16.0) \\ +(20.0) & +(14.0)\end{array}$

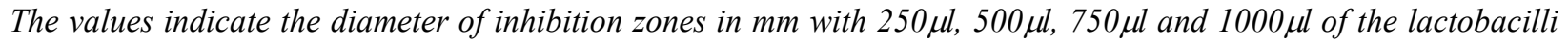
culture using agar spot and well-diffusion methods at 24hrs, $48 \mathrm{hrs}$ and 60 months.

\section{Discussion}

In this current study, no culturable colony was obtained from faecal specimen obtained from a 4-day old, low-birth weight, female neonate. As earlier suggested by Blakey et $a l^{23,25}$ and Sakata et $a l^{24,26}$, the absence of bacterial growth may be due to the immaturity of the digestive organs of the subject. Similarly, no lactobacilli were isolated from the faecal specimens of infants below 20 days old, which may be in accordance with the trend in the previous report of Yoshioka et al. ${ }^{25,27}$.

Nader de Macias $^{26}$ had previously documented that Lb. acidophilus and Lb. casei were the most prevalent Lactobacillus species in infantile faecal samples, while Axelsson ${ }^{27}$ also stated that $L b$. acidophilus, Lb. fermentum and Lb. salivarius were frequently reported ingredients of the faecal flora, and $L b$. casei, Lb. crispatus, Lb. gasseri, $L b$. plantarum, Lb. leichmanii and $L b$. reuteri were thought to be typical representatives. Isolate identification in the study of Pei-Pei et $a l^{28}$ also indicated that the infantile faecal Lactobacillus species belonged to Lb. acidophilus, Lb. salivarius and $L b$. paracasei. The observed inter-species differences in infantile faecal flora between the previous and current findings of this study, in which $L b$. reuteri and $L b$. acidophilus were the most prevalent, may be due to differences in diets and geographical locations. Murray ${ }^{29}$ in carrying out studies on Enterococcus spp. similarly reported that E. faecium and E. faecalis in humans are dependent on geographical location. However, there was no observable difference in the groups of bacterial species isolated from clinical specimens of gastroenteritic epidemic or hospital patients in this study, in comparison to other previous studies. Most of the aetiologic agents of gastroenteritis, affecting mainly infants in developing countries are therefore, still of the genera Bacillus, Citrobacter, Enterobacter, Escherichia coli, Klebsiella, Morganella, Proteus, Pseudomonas, Salmonella and Shigella, irrespective of the source of the pathogens Pei-Pei, et al. ${ }^{29}$.

In vitro antimicrobial activities have been known to vary with the infant's age and according to the different pathogens more common in infants of that age $^{24 .}$ Apart from a strain of Klebsiella aerogenes CD332, which was susceptible to all the test antibiotics, the gastroenteritic bacterial isolates were resistant to at least six of the 24 antibiotics tested. Multiple antibiotic resistance (MAR) rates of 
between $25.0 \%$ and $95.8 \%$ among the gastroenteritic bacterial strains were also observed in this study. It is known that several antimicrobial agents have become available for use in newborns and children with suspected or proven bacterial infections ${ }^{30}$ but the in vitro results of the antibiotic susceptibility of the gastroenteritic bacterial isolates to 30 oral paediatric antibiotic suspensions in this study gave relatively higher percentage resistance rates than expected in paediatric chemotherapy, most especially towards cotrimoxazole, metronidazole, erythromycin and chloramphenicol. This shows the great danger these commonly prescribed and abused antibiotics may pose in paediatric infectious conditions in the country, especially with the world-wide problems of antibiotic resistance ${ }^{31,32}$.

In addition to the clinical and public health implications of antibiotic resistance in paediatric chemotherapy, adverse side effects of such therapy, such as allergic reactions, renal toxicity, gastric intolerance, skin rashes, anaemia, antibioticassociated diarrhoea etc. are quite numerous and somehow very dangerous to infants and children. However, human breast milk has been reported to contain potential probiotic lactic acid bacteria; therefore, breastfeeding can be a significant source of lactic acid bacteria to the infant gut $^{23,33,34}$. The present study highlights the fact that Lactobacillus strains isolated from breastfed infants can clearly inhibit all the test target organisms even at 60 months of storage. $L b$. reuteri $\mathrm{CH} 1$ isolated from Nigerian breastfed infants had the lowest antibiotic resistance.

The findings of this study indicated the in vitro inhibitory activities of certain Lactobacillus strains towards gastroenteritic and reference bacterial species- Bacillus cereus, Bacillus licheniformis, Citrobacter sp., Enterobacter aerogenes, Escherichia coli, Klebsiella aerogenes, Klebsiella pneumoniae, Morganella morganii, Proteus mirabilis, Proteus vulgaris, Pseudomonas aeruginosa. Salmonella enterica var. Typhi, Salm. enterica var. Paratyphi, Salmonella enterica var. typhimurium, Salmonella sp., Shigella dysenteriae, Shigella flexneri, Staphylococcus aureus and Yersinia enterocolitica, even at 36 and 60 months of storage. The finally selected $L b$. reuteri $\mathrm{CH} 1$ strain was inhibitory against all the indicator and reference bacteria, even at 60 months of storage, had the lowest antibiotic resistance $(23.3 \%)$ and survived $3 \%$ bile and simulated $\mathrm{pH}$ conditions of 3.0-9.5, thereby having the potential properties of a probiotic.

The recovery of potential probiotic Lactobacillus candidates from faecal specimens of healthy breastfed Nigerian infants was confirmed by this study, indicating the beneficial significance of breastfeeding. This data can therefore, be used in promoting breast feeding in children. In addition, the low antibiotic resistance profiles of the probiotic candidates is of utmost importance in that the probiotics are not likely to participate in transference of antibiotic resistance to other bacterial flora in same ecological niche. Survival of the probiotic candidates in simulated $\mathrm{pH}$ conditions also infers their likely ability to survive in the gastrointestinal tracts of children, while producing inhibitory activities against gastroenteritic pathogens.

In conclusion, this study confirms that high quality, antimicrobial-producing Lactobacillus strains can be isolated from faecal specimens of breast-fed infants, especially older babies (5-11 months) who still receive complementary breast-feeding during weaning, thereby suggesting that nursing mothers, especially career-mothers, should not stop breast feeding of their children prematurely.

\section{Acknowledgements}

The authors acknowledge especially, Prof. Raffaelle Peluzzi, Centro Biologia Alpina Piora, Bellinzona, Switzerland, for provision of bacterial reference strains, Matron Giwa for assistance in obtaining parental consents for the collection of infantile faecal specimens, as well as Prof. (Mrs.) Akinkungbe of the Institute of Child Health and Prof. Nottidge of Department of Paediatric, University College Hospital, Ibadan, for provision of ethical permit.

\section{References}

1. Costello A. Hitting the mark: Can under-five mortality be cut by two thirds? Insights Health, 4 September 2003. Available from: http://www.mira.org.np/publication.htm

2. Edgar T, Boyd SD, Palamé MJ. Sustainability for behaviour change in the fight against antibiotic resistance: a social marketing framework J Antimicrob Chemother 2009; 63(2): 230-7.

3. Ogunshe AAO, Kolajo TT. In vitro phenotypic antibiotic resistance in bacterial flora of some indigenous orally consumed herbal medications in Nigeria. J Rural Trop Pub Health 2006; 5: 915. 
4. Ogunshe AAO, Bakare RA. Evaluation of antimicrobial agents on microbial pathogens of reproductive health importance in a developing country. J Fam Rep Health 2009; 3 (1): 9-18.

5. Ogunshe AAO. In vitro bactericidal effects and parental acceptance of indigenous probiotics in the control of infantile bacterial gastroenteritis. Int J Prob Preb 2006; 1(3/4): 233-44.

6. Vizoso Pinto MG, Franz CMAP, Schillinger U, Holzapfel WH. Lactobacillus spp. with in vitro probiotic properties from human faeces and traditional fermented products. Intl J Food Microbiol 2006; 109 (3): 205-14.

http://dx.doi.org/10.1016/j.ijfoodmicro.2006.01. $\underline{029}$

7. Ogunshe AAO, Olaomi JO. In vitro phenotypic bactericidal effects of indigenous probiotics on bacterial pathogens implicated in infantile bacterial gastroenteritis using Tukey-HSD test. Amer J Infect Dis 2008; 4(2): 162-7. http://dx.doi.org/10.3844/ajidsp.2008.162.167

8. Kale-Pradhan PB, Jassal HK, Wilhelm SM. Role of Lactobacillus in the prevention of antibioticassociated diarrhoea: a meta-analysis. Pharmacother 2010; 30(2): 119-26. http://dx.doi.org/10.1592/phco.30.2.119

9. Dop MC. Breastfeeding in Africa: will positive trends be challenged by the AIDS epidemic? Sante 2002; 12(1): 64-72.

10. WHO/CSTRBPIM. Effect of breastfeeding on infant and child mortality due to infectious diseases in less developed countries: a pooled analysis. WHO Collaborative Study Team on the Role of Breast-feeding on the Prevention of Infant Mortality. Lancet 2000; 355(9202): 451-5. http://dx.doi.org/10.1016/S0140-6736(00)82011-5

11. Hanson LA, Karlsson B, Jalil F. Antiviral and antibacterial factors in human milk. In: Hanson LA, editor. Biology of human milk. New York: Raven Press Ltd, 1988. pp. 141-57.

12. Bahl R, Frost C, Kirkwood BR, Edmond K, Martines J, Bhandari N, Arthur P. Infant feeding patterns and risks of death and hospitalization in the first half of infancy: multicentre cohort study. Bull WHO 2005; 83(6): 418-26.
13. Klessen B, Bezirtzoglou E, Matto J. Culturebased knowledge on biodiversity, development and stability of human gastrointestinal microflora. Microb Ecol Health Dis (supplements), 2000; 2: 53-63.

14. Cheesborough M. District Laboratory Practice in Tropical Countries, Part-2. New York: Cambridge University Press; 2000.

15. De Mann JC, Rogosa M, Sharpe ME. A medium for the cultivation of lactobacilli. $J$ Appl Bacteriol 1960; 23: 130-5.

16. Kandler O, Weiss N. The genus: Lactobacillus. P. 1208-1260. In Sneath PHA, Mair NS, Sharpe ME, Holt JG, editors. Bergey's Manual of Systematic Bacteriology, vol.2. Baltimore: Williams and Wilkins, 1986. pp. 1209-34.

17. Molin G, Jeppsson B, Ahrnè S, Johansson ML, Nobek S, Stahl M, Bengmark S. Numerical taxonomy of Lactobacillus species associated with healthy and diseased mucosa of the human intestines. J Appl Bacteriol 1993; 74: 314-23.

18. National Committee for Clinical Laboratory Standards. Performance standards for antimicrobial disk susceptibility tests. NCCLS Document M2A8. 8th edition. USA: Wayne Pa; 2003.

19. Ogunshe AAO. Bioinhbition of diarrheogenic Gram-positive bacterial pathogens by potential indigenous probiotics in industrial infant weaning food. Asian Pacif J Trop Med 2008; 1 (2), 7-11.

20. Tagg JR, Dajani AS. Wannamaker LW. Bacteriocins of Gram-positive bacteria. Bacteriol Revs 1976; 40: 722-56.

21. Vallado M, Sandine WE. Standardized method for determining the effect of various antibiotics on lactococcal cultures. J Food Prot 1994; 57: 235-9.

22. Elaine E, Vaughan EC, Looney R, O'Rourke N, Coveney H, Daly C, Fitzgerald GF. Isolation from food sources of lactic acid bacteria that produced antimicrobials. J Appl Bacteriol 1994; 76: 118-23. 
23. Blakey JL, Lubitz L, Barnes GL, Bishop RF, Campbell NT, Gillam GL. Development of gut colonisation in pre-term neonates. $J \mathrm{Med}$ Microbiol 1982; 15 (4): 519-29.

http://dx.doi.org/10.1099/00222615-15-4-519

24. Sakata H, Yoshioka H, Fujita K. Development of the intestinal flora in very low birth weight infants compared to normal full-term newborns. Eur J Paediatr, 1985; 144: 186-90.

25. Yoshioka H, Iseki K, Fujita K. Development and differences of intestinal flora in the neonatal period in breast-fed and bottle-fed infants. Pediatr 1983; 72: 317-21.

26. Nader de Macias ME, Apella MC, Romero NC, Gonzalez SN, Oliver G. Inhibition of Shigella sonnei by Lactobacillus casei and Lactobacillus acidophilus. J Appl Bacteriol 1992; 73: 407-11.

27. Axelsson L. Lactobacillus reuteri, a member of the gut microflora. PhD Dissertation, Swedish University, Sweden. 1990.

28. Pei-Pei L, You-Miin H, Cheng-Chih $\mathrm{T}$. Antagonistic activity of Lactobacillus acidophilus RY2 isolated from healthy infancy feces on the growth and adhesion characteristics of enteroaggregative Escherichia coli. Anaer, 2009; 15 (4): 122-6.

http://dx.doi.org/10.1016/j.anaerobe.2009.01.009
29. Murray BE. The life and times of the Enterococcus. Clinical Microbiol Revs 1990; 9: 40-62.

30. Siegel JD. Neonatal sepsis. Semin. Perinatology 1985; 9: 20.

31. Qin X, Razia Y, Johnson JR, Stapp JR, Boster DR, Tsosie T, Smith DL, Braden CR, Gay K, Angulo FJ, Tarr PI. Ciprofloxacin-resistant Gram-negative bacilli in the fecal microflora of children. Antimicrob Agents Chemother 2006; 50 (10): 3325-9. http://dx.doi.org/10.1128/AAC.00548-06

32. Ogunshe AAO, Fawole AO, Ajayi VA. Microbial evaluation of public health implications of urine as alternative therapy in paediatric cases. Pan Afr Med J 2010; 5 (12):

33. Martín R, Langa S, Reviriego C, Jimínez E, Marín ML, Xaus J, Fernández L, Rodríguez JM. Human milk is a source of lactic acid bacteria for the infant gut. Pediatr 2003; 143(6), 754-8.

34. Martín R, Heilig GH, Zoetendal EG, Smidt H, Rodríguez JM. Diversity of the Lactobacillus group in breast milk and vagina of healthy women and potential role in the colonization of the infant gut. J Appl Microbiol 2007b; 103(6): 2638-44. http://dx.doi.org/10.1111/j.13652672.2007.03497.x 